\title{
Destabilisation of Water-in-Crude Oil Emulsions by Silicone Copolymer Demulsifiers
}

\author{
D. Daniel-David1*, A. Le Follotec 1,2, I. Pezron', C. Dalmazzone², C. Noïk², L. Barré2 \\ and L. Komunjer ${ }^{1}$ \\ 1 Laboratoire Génie des Procédés Industriels, UMR CNRS 6067, Université de Technologie de Compiègne, 60205 Compiègne - France \\ 2 Institut français du pétrole, 1-4 avenue de Bois-Préau, 92852 Rueil-Malmaison - France \\ e-mail: ddanield@utc.fr - alefollo@utc.fr - isabelle.pezron@utc.fr - christine.dalmazzone@ifp.fr - christine.noik@ifp.fr - \\ loic.barre@ifp.fr - lea.metlas@utc.fr \\ * Corresponding author
}

\begin{abstract}
Résumé - Déstabilisation des émulsions eau dans pétrole brut par des polymères siliconés désémulsionnants - Des émulsions stables de type eau dans huile se forment lors de la production de pétrole brut. Les asphaltènes, molécules tensioactives naturellement présentes dans le pétrole, créent un film viscoélastique qui empêche les gouttelettes d'eau de coalescer. La séparation de l'eau par l'ajout de tensioactifs désémulsionnants est indispensable avant l'étape du raffinage. Récemment, des formulations à base de copolymères polyéther siliconés ont prouvé leur efficacité et leur caractérisation aux interfaces eau/air et eau/pétrole a été effectuée. Différents mécanismes de désémulsification peuvent être envisagés: (i) dissolution des agrégats d'asphaltènes ou (ii) déplacement de ceux-ci dû à l'adsorption des polysiloxanes à l'interface eau/pétrole. Afin d'élucider le type de mécanisme, diverses techniques ont été utilisées pour étudier les interactions entre asphaltènes et copolymère : rayons $\mathrm{X}$ aux petits angles permettant d'étudier une éventuelle influence du copolymère sur la taille des agrégats d'asphaltènes, capacité du copolymère à chasser les agrégats d'asphaltènes préalablement adsorbés sur des billes de silice (modélisant les gouttelettes d'eau), microscopie à force atomique utilisée pour observer l'action du copolymère sur la structure des films asphalténiques.
\end{abstract}

\footnotetext{
Abstract - Destabilisation of Water-in-Crude Oil Emulsions by Silicone Copolymer Demulsifiers Asphaltene aggregates are known to form viscoelastic film preventing the coalescence of droplets in water-in-oil emulsions formed during crude oil exploitation. Since phase separation is necessary for oil refining process, demulsifying additives are used. It was found that formulations based on polysiloxane copolymers promote separation of water from crude oil even at very low concentration (few tens of ppm). Two alternative scenarios of emulsion destabilisation can be envisaged: (i) dissolution of asphaltene aggregates or (ii) displacement of the asphaltene network by adsorption of the more surface active copolymer into void sites at the oil/water interface. In order to reveal the mechanism of destabilisation, interactions between asphaltene aggregates and copolymer were explored. For that purpose various techniques have been employed: small angle X-ray scattering allowing the determination of the influence of copolymer on the size of asphaltene aggregate; capacity of copolymer to displace asphaltene aggregates initially adsorbed on silica particles (which simulate water droplets); Atomic Force Microscopy (AFM) was used to observe the influence of copolymer on the interfacial structure of asphaltene films spread on water surface.
} 


\section{INTRODUCTION}

Crude oil exploitation is always accompanied with water production. Water which is naturally present in oil reservoirs mixes with crude oil to form very stable emulsions due to very high shear rates and zones of turbulence encountered at the wellhead in the choke-valve. Water-in-oil (W/O) emulsions are preferentially created because of the oil soluble nature of the stabilizing compounds. This kind of emulsion can be very stable due to the presence of native surfactants such as asphaltenes and resins, which play the role of emulsifiers but also because of small solid particles (crystallized waxes and clays for example) [1-4]. W/O emulsion is undesired since its volume and viscosity, being higher than that of crude oil, raise operational costs. Thus, before refining, water content has to be reduced in order to produce high-quality oil. Dehydration of crude oil is usually achieved by gravitational separation or electrocoalescence [5]. When required times for demulsification are long, chemical agents are used to speed up the process. Blends of surfactants are commonly used: amines, copolymers of ethylene oxide and propylene oxide, ethoxylated phenols, and others; they are formulated in solvents like short-chain alcohols, aromatic or heavy aromatic naphta [6-8].

Stability of water-in-crude oil emulsions is attributed to asphaltenes and resins, which prevent droplet coalescence by forming a rigid film or skin at the interface $[9,10]$. Asphaltenes and resins have the same chemical composition but their molecular weight is different. Asphaltenes are defined as the crude oil fraction insoluble in $n$-heptane or $n$ pentane but soluble in toluene while resins are soluble in aliphatic and aromatic solvents (except in methanol). They both contain hydrophobic and hydrophilic moieties, which confer the amphiphilic character and respective surfaceactive properties. In crude oil, aggregates of asphaltenes are kept in dispersed state by resins [11] but when crude oil is suddenly brought in contact with water, asphaltenes and resins compete for the water/oil interface [7]. Resins, which are lighter than asphaltenes, are the first entities to reach the water/oil interface; this provokes a change in asphaltene solubility resulting in accumulation of the asphaltene entities around the water droplets. The emulsion stability is known to be related to the state of the asphaltene aggregates [9] but the form in which asphaltenes stabilize water-in-oil emulsions still remains controversial $[10,12,13]$. It is now admitted that the emulsion stability is due to an asphaltenic network, containing also smaller native surfactants such as resins and naphtenic acids $[9,14,15]$. It is generally believed that the presence of resin decreases film rigidity and diminish emulsion stability [7, 16, 17]. Ese et al. [18] showed by AFM that the addition of resins into asphaltene monolayers caused the opening of the rigid asphaltene structure and that the presence of demulsifiers had the same effect. In addition, presence of demulsifiers enhances the film drainage before its rupture: Bhardwaj and Hartland [19] have shown that efficient demulsifiers reduce the interfacial tension between oil and water but also displace the native surfactants in order to adsorb at the interface. While decreasing interfacial tension and adsorbing at the interface are the two essential properties of demulsifiers, they alone are not sufficient [20]. Demulsifiers have to show high diffusion/adsorption rate and also be able to influence the viscoelastic properties of the interfacial film. Efficient demulsifiers have to adsorb at the interface before interacting with the asphaltene network. Demulsifiers that are only water soluble are not good emulsion breakers and amphiphilic demulsifiers are preferred [19, 21]. In our previous reports, the action of a linear polysiloxane demulsifier (copolymer A) on crude oil/water interface was studied using a liquid/liquid Langmuir trough [22], subsequent to its characterization at the air/water interface [23]. The demulsifier was compared to two other polysiloxane copolymers (copolymers B and C) having similar structure but different demulsification efficacy. The results confirmed that amphiphilic character is a major factor determining demulsification ability. Indeed, the two amphiphile copolymers (A and B) were good emulsion breakers while the entirely hydrophobic copolymer was inefficient $[22,23]$. The determination of elastic modulus during the compression of crude oil/water interface by means of a liquid/liquid Langmuir trough showed that amphiphilic copolymers reach the interface spontaneously; from this observation the hypothesis that the asphaltene film could be displaced by the copolymers followed. Detailed investigations of the action of these molecules are presented here. Two alternative scenarios have been envisaged:

- the dissolution of the asphaltene entities in presence of copolymer, or

- the displacement of asphaltene network from the crude oil/water interface by the more surface active copolymer.

The interactions between asphaltenes and polysiloxane copolymer were studied using small-angle X-ray scattering (SAXS) and atomic force microscopy (AFM). SAXS was shown to allow the investigation of the size of asphaltene aggregate in solution [24, 25] while AFM was used [18, 26] to show that demulsifiers alter the mechanical strength of the asphaltene films.

The ability of the polysiloxane copolymer to displace asphaltene aggregates initially adsorbed on hydrophilic silica particles was also determined. This modus operandi was selected taking into consideration the asphaltene ability to adsorb onto mineral surfaces due to its amphiphilic character. Concerning the interactions of asphaltenes with solid silica particles, we rely on the fact that non treated silica particles are known to be hydrophilic. The interactions of polysiloxane copolymer A with spread asphaltene films on water surface were investigated using AFM imaging of transferred films. 


\section{EXPERIMENTAL PROCEDURE}

\subsection{Material}

Demulsifiers A-C are silicone copolymers based on polyalkylene oxide modified poly(dimethysiloxane) chains (Fig. 1), provided by GE Silicones, Switzerland. Their average molecular weights were, respectively, 2100, 2000 and $2800 \mathrm{~g} / \mathrm{mol}$. Samples A and $\mathrm{B}$ are poly(ethyleneoxide)-poly(dimethylsiloxane)-poly(ethyleneoxide) block copolymers. PEO moieties represent 55\% and $40 \%$ of their respective molecular weight. Polysiloxane $\mathrm{C}$ is a poly(propyleneoxide)-poly(dimethylsiloxane)-poly(propyleneoxide) block copolymer with $55 \%$ of PPO. Asphaltenes were extracted from Safaniya vaccum residue by precipitation in an excess of n-heptane, according to the NF T60-115 method. Their density was $1.1207 \mathrm{~g} / \mathrm{cm}^{3}$ at $25^{\circ} \mathrm{C}$. The silica particles were furnished by Potters Industry Inc. (grade 110P8, mean size $11 \mu \mathrm{m}$, non porous). They are hollow spherical particles composed of approximately $0.5 \mu \mathrm{m}$ thick glass shell. Their diameter is big enough to prevent aggregation due to van der Waals forces and their weight is small enough to avoid gravitational sedimentation. The BET specific surface area was $1 \mathrm{~m}^{2} / \mathrm{g}$.

\subsection{Methods}

\subsubsection{Determination of Radius of Gyration and of Molecular Weight of Asphaltene Aggregates}

SAXS was used to determine the radius of gyration and the molecular weight of the asphaltene aggregates in solution.
The asphaltene aggregates were dispersed in toluene (Rectapur $^{\mathrm{TM}}$ Prolabo) $(3 \% \mathrm{w} / \mathrm{w})$. Concentration of demulsifier was $5000 \mathrm{ppm}(0.5 \% \mathrm{w} / \mathrm{w})$. This copolymer concentration was selected in relation to asphaltene concentrations in such a way to assure two distinct electronic density domains. For higher polysiloxane concentrations, the contrast term between the solvent and the system formed by copolymers and asphaltenes would not be sufficient to guarantee reliable values for the radii of gyration and molecular weights. The measurements were performed with a $\mathrm{Cu}$ rotating anode (Rigaku) providing an X-ray beam (1.54 ̊̊), a curved coated gold mirror combined with a $\mathrm{Ni}$ filter, and one-dimensional position-sensitive proportional counter (Elphyse). The detector had a resolution of $150 \mu \mathrm{m}$. The X-ray generator was operated at $1 \mathrm{~kW}(40 \mathrm{kV} \times 25 \mathrm{~mA})$. The $q$ range investigated was between 0.01 and $0.18 \AA^{-1}$ and the distance from sample to the detector was $82 \mathrm{~cm}$. Samples were placed in a $1.9 \mathrm{~mm}$ diameter sealed glass capillary. All measurements were done at ambient temperature $\left(21^{\circ} \mathrm{C}\right)$. Experimental data were converted to an absolute scale. The overall precision is estimated to be $10 \%$ and corresponds to the transformation of relative intensity to the absolute cross-section values. This transformation takes into account the incident flux, thickness of the sample and its transmission.

The intensity scattered per unit of volume for the simplest model of a two-phase system (in present case asphaltene aggregate and solvent) is given by the following equation [24, 27]:

$$
I(q)=C_{r} n_{e} v\left(\rho_{1}-\rho_{2}\right)^{2} F(q) S(q)
$$

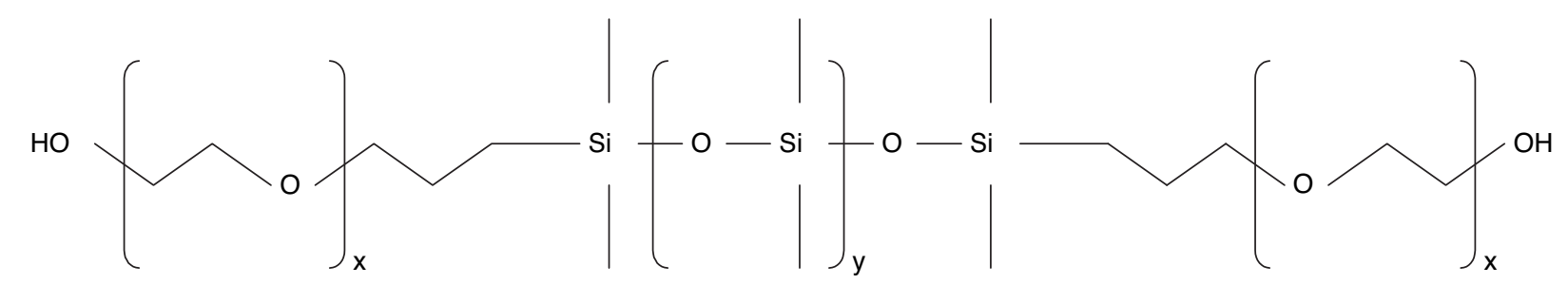

a)

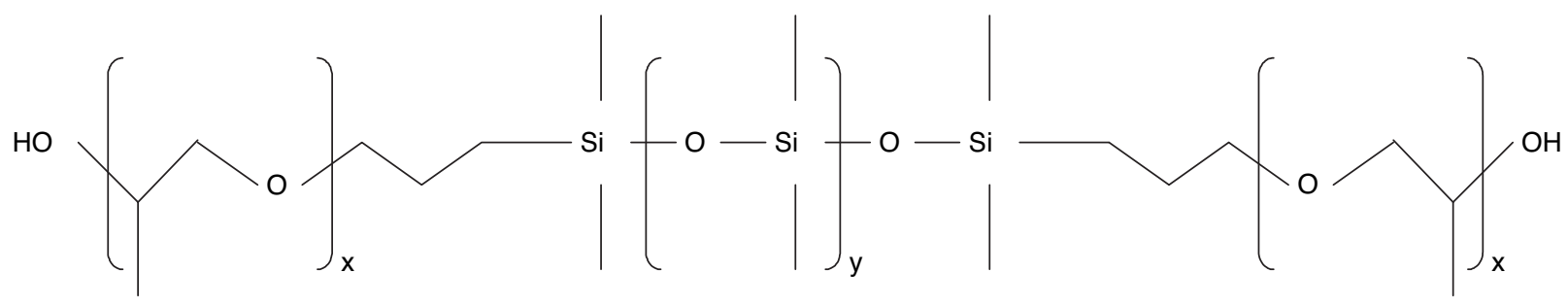

b)

Figure 1

(a) General formula of copolymers A and B ( $x=12, y=11$ and $x=8, y=14$ respectively).

(b) General formula of copolymer C $(x=13$ and $y=15)$. 
where $C_{r}$ is a constant dependent on the radiation used, $n_{e}$ is the number of particles present in the sample in volume unit, $v$ is their volume (it is considered identical for all particles), $\left(\rho_{1}-\rho_{2}\right)$ is the contrast term where $\rho_{1}$ and $\rho_{2}$ are the scattering densities of the asphaltene aggregates and the solvent (toluene), respectively (see Table 1 for values). This term is calculated by knowing the elemental composition of asphaltenes (see Table 2). $F(q)$ is the particle form factor $(F(q=0)=v)$ and $S(q)$ is the structure factor, which is dependent on the interparticle interactions.

TABLE 1

Contrast terms of Safaniya asphaltenes, toluene and copolymers A-C

\begin{tabular}{c|c}
\hline & Contrast term $\left(\mathrm{e}^{-} / \AA^{3}\right)$ \\
\hline asphaltenes & 0.36 \\
\hline toluene & 0.28 \\
\hline Copolymer A & 0.35 \\
\hline Copolymer B & 0.34 \\
\hline Copolymer C & 0.33 \\
\hline
\end{tabular}

TABLE 2

Elemental analysis of Safaniya asphaltenes (\% in weight)

\begin{tabular}{c|c}
\hline Element & Content $(\%, w / w)$ \\
\hline carbon & 82.5 \\
\hline hydrogen & 7.49 \\
\hline oxygen & 1.37 \\
\hline nitrogen & 1.01 \\
\hline sulfur & 7.5 \\
\hline
\end{tabular}

The measured intensity $d I(q)$ is given as a function of the differential cross section $\frac{d \sigma}{d \Omega}(q)$ (the fraction of X-ray beam scattered into an element of solid angle $d \Omega$ ) as follows [24,27]:

$$
d I(q)=T_{r} I_{0} e \frac{d \sigma}{d \Omega}(q) d \Omega
$$

where $e$ is the sample thickness $(\mathrm{cm})$ and $T_{r}$ is the sample transmission $\left(T_{r}=\frac{I}{I_{0}}\right)$.

The scattering differential cross section (or scattering intensity) in the small- $q$ or Guinier region, is given by the following expression according to the Zimm approximation [24], which is based on the hypothesis that the particle concentration is sufficiently low so that the interactions between particles are negligible (and $S(q)=1$ ):

$$
\frac{1}{\frac{d \sigma}{d \Omega}(q)}=\frac{1}{\frac{d \sigma}{d \Omega}(q=0)}\left(1+\frac{q^{2} R_{g}{ }^{2}}{3}\right)
$$

In the following sections and Figure 2, $I(q)$ will refer to $\frac{d \sigma}{d \Omega}(q)$ after absolute scale treatment.

By plotting $\frac{1}{I(q)}=f\left(q^{2}\right)$, one can deduce from the slope the square of the radius of gyration of the asphaltene aggregates $R_{g}{ }^{2}$.

The molecular weight of the asphaltene aggregates can be obtained by extrapolation of Equation 3 to $q=0$ as follows:

$$
\frac{d \sigma}{d \Omega}(q=0)=I(0)=C_{r} n_{e} v^{2}\left(\rho_{1}-\rho_{2}\right)^{2}=\frac{C_{r}}{N_{a}} c M\left(\frac{\rho_{1}-\rho_{2}}{d}\right)^{2}
$$

where $c$ is the weight concentration of asphaltenes, $M$ the asphaltene aggregate molecular weight, $d$ the asphaltene density and $N_{a}$ the Avogadro number.

For a polydisperse system, the weight average molecular weight will be obtained:

$$
\begin{aligned}
\frac{d \sigma}{d \Omega}(q=0)=I(0) & =\frac{C_{r}}{N_{a}}\left(\sum_{i} c_{i} M_{i}\right)\left(\frac{\rho_{1}-\rho_{2}}{d}\right)^{2} \\
& =\frac{C_{r}}{N_{a}} c M_{w}\left(\frac{\rho_{1}-\rho_{2}}{d}\right)^{2}
\end{aligned}
$$

where $c_{i}$ is the concentration of asphaltene aggregate $i$, of molecular weight $M_{i}$.

$c$ is the total concentration defined as: $c=\sum_{i} c_{i}$

The weight-averaged molecular weight $M_{w}$ is expressed as:

$$
M_{w}=\frac{\sum_{i} c_{i} M_{i}}{\sum_{i} c_{i}}=\frac{\sum_{i} n_{i} M_{i}^{2}}{\sum_{i} n_{i} M_{i}}
$$

where $n_{i}$ is the number of aggregates of molecular weight $M_{i}$.

The average radius of gyration $R_{g}$ obtained is the $z$-average of the square radius of gyration:

$$
R_{g, z}^{2}=\frac{\sum_{i} c_{i} M_{i} R_{g_{i}}{ }^{2}}{\sum_{i} c_{i} M_{i}}=\frac{\sum_{i} n_{i} M_{i}^{2} R_{g_{i}}{ }^{2}}{\sum_{i} n_{i} M_{i}^{2}}
$$

where $R_{g_{i}}$ is the radius of gyration of aggregate $i$.

\subsubsection{Influence of Demulsifier on Adsorbed Asphaltenes}

Asphaltenes were adsorbed on silica particles at the conditions of complete saturation of the silica surface. Five asphaltene 
solutions were prepared in toluene (Rectapur ${ }^{\mathrm{TM}}$ Prolabo) in which $0.22 \mathrm{~g}$ of silica powder were added. The initial asphaltene concentration is written as $C_{i}$. The obtained dispersions were gently stirred at $23^{\circ} \mathrm{C}$ during five hours. Then, the copolymer was injected in four dispersions at concentrations ranging from 100 to $10000 \mathrm{ppm}$ i.e. 0.01 to $1 \% \mathrm{w} / \mathrm{w}$ (100, 1000,5000 and $10000 \mathrm{ppm}$ approximately); the fifth dispersion was used to measure the amount of adsorbed asphaltene with no copolymer present. After one-hour contact, the samples are filtered trough $0.45 \mu \mathrm{m}$ PTFE filters and the asphaltene concentration in the supernatant, $C_{f}$, was determined by measuring the absorbance at $750 \mathrm{~nm}$ with a UV/VIS spectrometer Lambda 12 (Perkin Elmer). Calibration curve (absorbance $v s$. asphaltene concentration) was used to convert absorbance into the asphaltene concentration. The final adsorbed amount $\Gamma$ was calculated as follows:

$$
\Gamma=\frac{m_{a}\left(C_{i}-C_{f}\right)}{m_{s} S_{B E T}}
$$

where $m_{a}$ is the asphaltene mass in solution $(1.33 \mathrm{~g}), m_{s}$ is mass of silica powder while $S_{B E T}$ represents specific surface area of silica powder.

\subsubsection{AFM Imaging}

Asphaltene films were transferred from air/water interface onto glass plate via Langmuir-Blodgett deposition. The glass plate was first immersed in the water subphase before the asphaltene film was spread. The film was compressed to the surface pressure corresponding to the close packed structure of the interfacial layer (just below the film collapse) with a speed of 5 $\mathrm{mm} / \mathrm{min}$. The film was then transferred onto plate by pulling the plate up at a $5 \mathrm{~mm} / \mathrm{min}$ speed while interfacial area was kept constant. All experiments were performed at $23^{\circ} \mathrm{C}$.

AFM imaging was carried out in tapping mode, in air using Dimension 3100 Nanoscope IIIa AFM (Digital Instruments, Inc.).

\section{RESULTS AND DISCUSSION}

\subsection{SAXS}

The influence of addition of $5000 \mathrm{ppm}$ of polysiloxane into solution of asphaltene is presented in Figure 2. From low $q$ part of the SAXS spectre the values of $R_{g}$ and molecular weight of aggregates were calculated by plotting the inverse of scattering intensity as a function of $q^{2}$ (Fig. 3). Obtained radii of gyration and molecular weights are summarized in Table 3. By bearing in mind that the precision of the data is $10 \%$ one concludes that none of polysiloxane molecules presents significant influence on asphaltene aggregate dissociation. This conclusion is also suggested by the fact that all curves are superposing near the Guinier regime (see Figs. 2, 3).

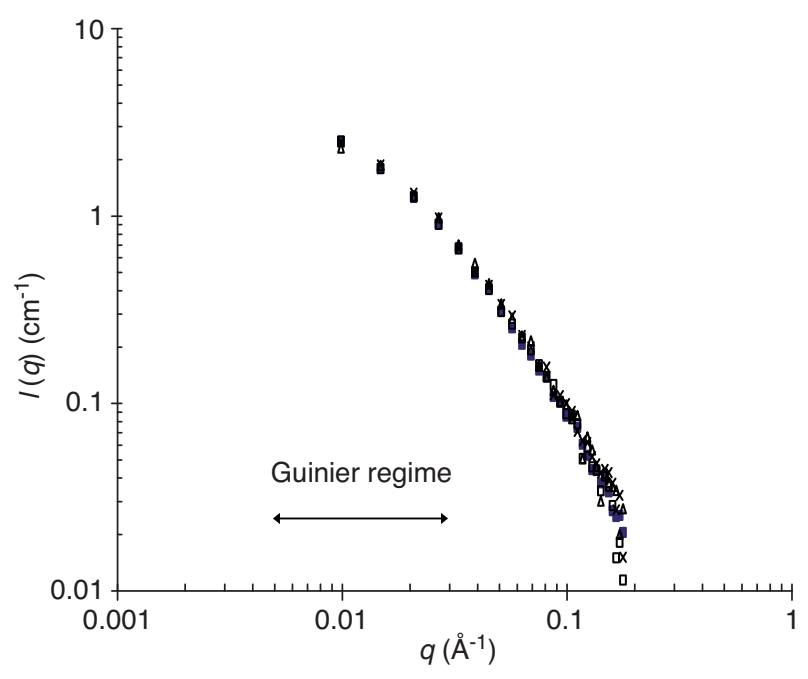

Figure 2

SAXS spectra of asphaltene solutions in toluene $(3 \% \mathrm{w} / \mathrm{w})$ : pure solution (filled squares), copolymer A (empty squares), copolymer B (empty triangles), copolymer C (crosses). Concentration of copolymer in solution is $0.5 \% \mathrm{w} / \mathrm{w}$ (5000 ppm).

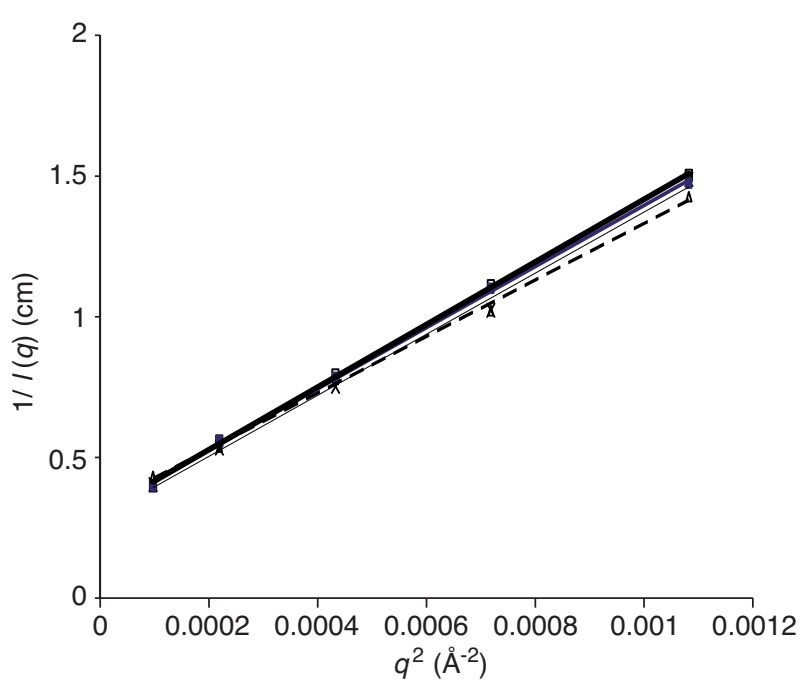

Figure 3

Inverse of scattering intensity versus $q^{2}$ : pure solution (filled squares and full line for best fit), copolymer A (empty squares and bold full line for best fit), copolymer B (empty triangles and bold dotted line for best fit), copolymer C (crosses and dotted dots for best fit). Concentration of copolymer in solution is $0.5 \% \mathrm{w} / \mathrm{w}(5000 \mathrm{ppm})$. 
TABLE 3

Effect of copolymer addition on the radius of gyration (angstrom) and the average molecular weight $(\mathrm{g} / \mathrm{mol})$ of Safaniya asphaltenes in solution in toluene. Concentrations of asphaltenes and copolymers are $3 \%$ and $0.5 \% \mathrm{w} / \mathrm{w}(5000 \mathrm{ppm})$ respectively

\begin{tabular}{lcc}
\hline & $\begin{array}{c}\text { Radius of } \\
\text { gyration }(\AA)\end{array}$ & $\begin{array}{c}\text { Molecular weight } \\
(\mathrm{g} / \mathrm{mol})\end{array}$ \\
\hline Pure asphaltenes & 106 & 196800 \\
\hline Asphaltenes + copolymer A & 112 & 174300 \\
\hline Asphaltenes + copolymer B & 99 & 146400 \\
\hline Asphaltenes + copolymer C & 97 & 145400 \\
\hline
\end{tabular}

Earlier SAXS studies dealing with the dispersing effect of resins [28] and the influence of temperature [27] report significant changes in asphaltene size thus proving that technique is well suited for such measurements. Consequently, we infer that the three copolymers have no effect on the size of asphaltene aggregates in toluene. It seems reasonable to suppose that one can extrapolate these results to the asphaltene-copolymer interactions at crude oil/water interface. This assertion would then constitute a first step in the validation of the hypothesis of asphaltene network displacement from the interface by copolymers A and B, which are found to be efficient emulsion breakers.

\subsection{Polysiloxane Mediated Desorption of Asphaltene from Silica Particles}

The variation of surface excess $\Gamma$ as a function of copolymer concentration is presented in Figure 4. Asphaltenes were first adsorbed onto silica particles then the polymers were added at concentrations ranging from 100 to $10000 \mathrm{ppm}$ and the quantity of desorbed asphaltenes was subsequently measured. As shown in previous studies, the copolymer ability to disturb the asphaltene film can be interpreted as the competitive effect of co-adsorbents [29, 30]. All copolymers were able to diminish the adsorption of asphaltene aggregates on silica particles. Nevertheless, the effect was more pronounced for copolymers A and B, which have similar structure. The effect of hydrophobic copolymer $\mathrm{C}$ was weaker, confirming that the amphiphilic character is necessary condition for diminishing asphaltene adsorption. Asphaltene adsorption usually depends on various parameters such as the origin [31], the nature of mineral surface [32], the nature of solvent [32] and eventual presence of co-adsorbents (resins) $[29,30]$. Although some reports proposed a multilayer-type adsorption [31, 33, 34], the adsorption isotherms of asphaltenes seem to be Langmuir-type [29, 32, 35]. It has been stated in the literature that adsorption of polyoxyalkylene surfactants onto siliceous particles are due to electrostatic or polar interactions involving hydrogen bonding with oxygen atoms in the oxyalkylene chains [36] and hence

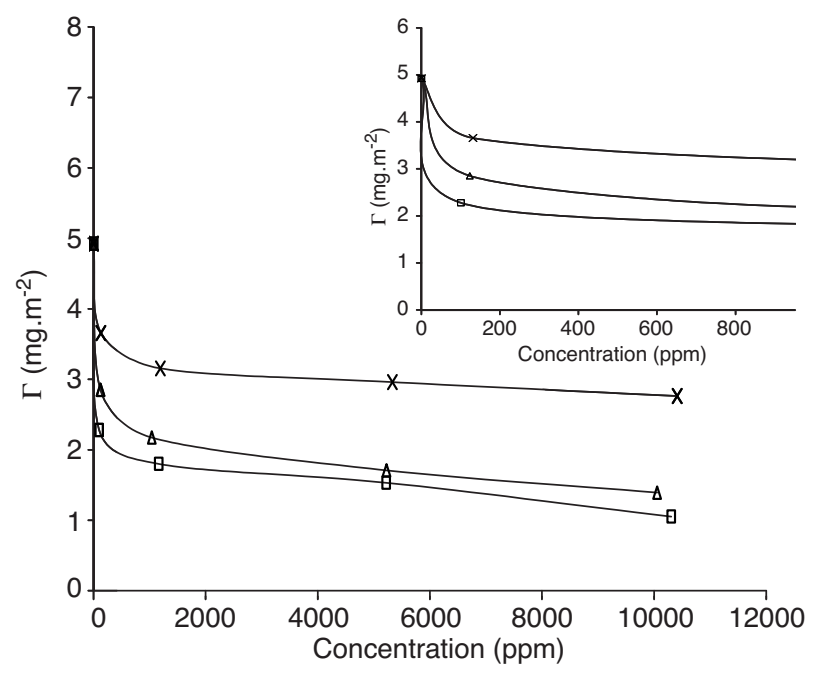

Figure 4

Desorption of asphaltenes from silica particles caused by copolymers A (empty squares), B (empty triangles), C (crosses). Region of low concentrations is given in insert. Lines serve as guide for the eyes only.

adsorption of such polymers should increase with the number of ethylene oxide groups and decrease with the number of propylene oxide groups [37]. One can envisage that the efficient emulsion breakers polymers A and B provoke desorption of asphaltene aggregates from silica particle surface followed by adsorption of copolymers. However, the present experiments do not directly prove that the copolymers have in fact replaced the asphaltenes on the silica surface. Thus the actual mechanism of crude oil/water emulsion destabilisation is presently based on a conjecture: copolymer first adsorbs at the oil/water interface, as it was shown in previous liquid/liquid Langmuir experiments [22] and then displaces asphaltene film from the interface.

\subsection{AFM Images}

AFM images of pure asphaltene film and the asphaltene film containing 100 ppm of copolymer A are shown in Figures 5. Pure asphaltene film is dense and the bead-like network of asphaltene aggregates as can be clearly seen in Figure 5a. In presence of copolymer A, bare areas appear within the asphaltene network (Fig. 5b). These blank areas look like as if copolymer A has pressed the asphaltene aggregates away.

The comparison between the topography profiles of the two films furnishes quantitative proofs to this assumption (Fig. 6): the asphaltene film thickness increases in presence of copolymer. Indeed, an asphaltene bead measured in 


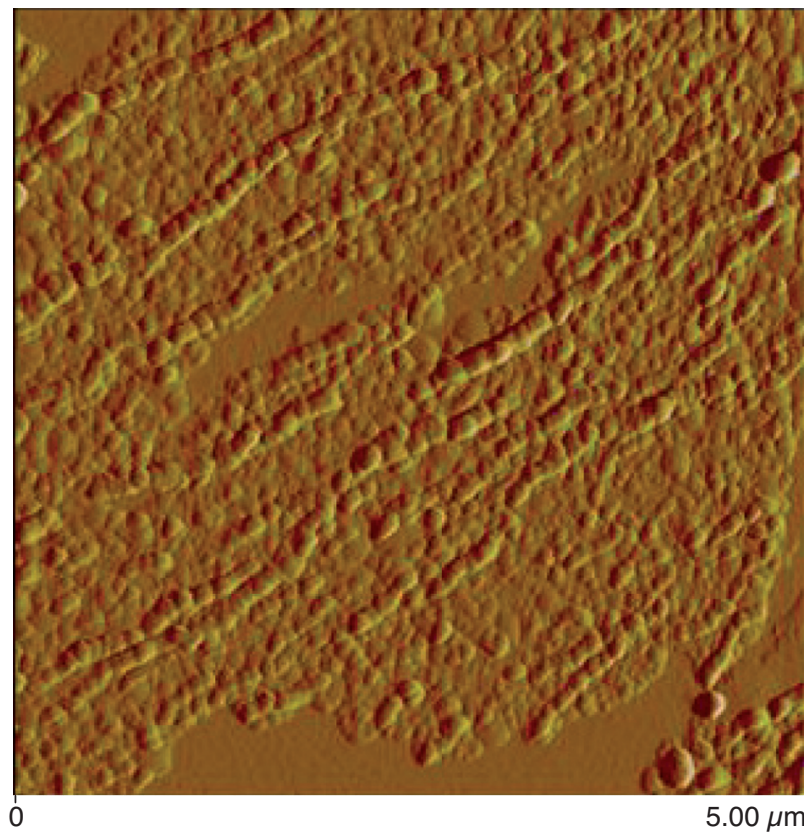

a)

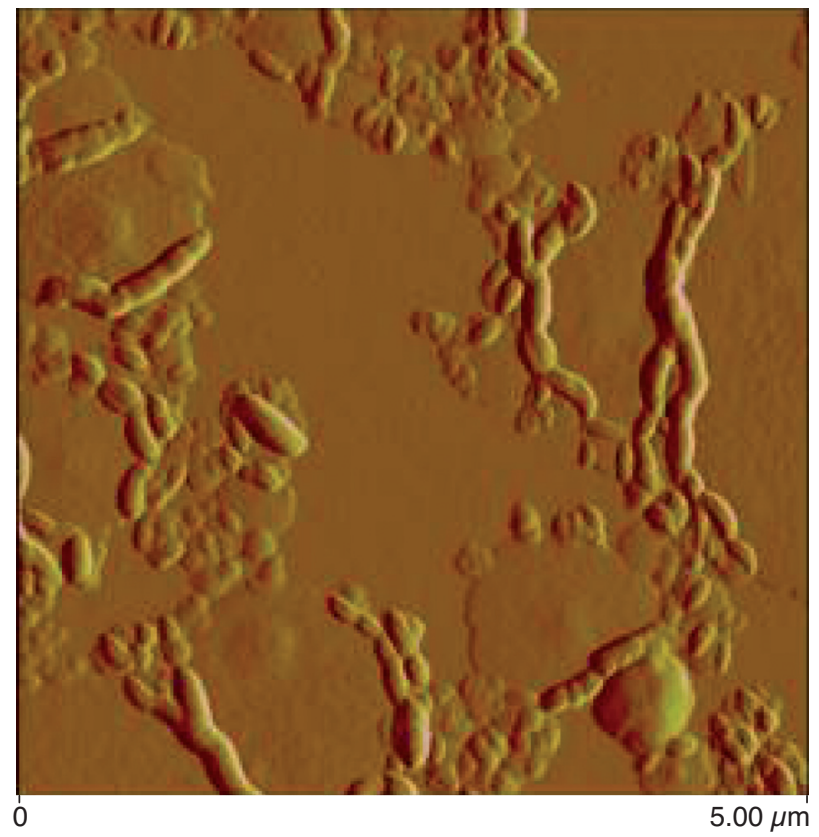

b)

Figure 5

(a) Tapping AFM image of pure asphaltene film deposited onto glass by Langmuir-Blodgett method; concentration of asphaltene in deposited solution is $0.1 \% \mathrm{w} / \mathrm{w}$. (b) Tapping AFM image of mixed asphaltene/copolymer A film deposited onto glass by Langmuir-Blodgett method; concentrations of asphaltenes and copolymer A in deposited solution are $0.1 \% \mathrm{w} / \mathrm{w}$ and $0.01 \% \mathrm{w} / \mathrm{w}(100 \mathrm{ppm})$ respectively.

Figure 6a is estimated to about $28 \mathrm{~nm}$ high and $78 \mathrm{~nm}$ wide while in presence of copolymer A (Fig. 6b), height of most asphaltene entities is superior to $50 \mathrm{~nm}$ (the selected area is $86 \mathrm{~nm}$ high and $166 \mathrm{~nm}$ wide). These results agree with the alteration of the asphaltene structure observed by Ese et al. in presence of resins and demulsifier molecules [18].

The results presented in this report allow formulating a mechanism of emulsion destabilisation in presence of polysiloxanes A and B. The copolymer first adsorbs at the crude $\mathrm{oil} /$ water interface into the packing defects of asphaltene network due to its high affinity for the oil/water interface. It accumulates at the oil/water interface creating "copolymerrich domains", inducing condensation in the asphaltene network allowing the water droplets to coalesce. Proposed mechanism is thus quite similar to the interactions of surfactants with viscoelastic protein films [38].

\section{CONCLUSION}

Various techniques have been used to elucidate the destabilisation mechanism of water-in-crude oil emulsions by polysiloxane copolymers. Present work is a continuation of the previous study where the correlation between the elasticity of the interfacial film at low surface pressure and the capacity of the copolymer to interact with native surfactants in crude oil was established. At the present time the proposed destabilisation mechanism is as follows: the copolymer first adsorbs at the crude oil/water interface into packing defect sites due to its high affinity for the oil/water interface. Then, the copolymer molecules disrupt the network of asphaltene aggregates inducing the emulsion break-up. We also confirmed that amphiphilic characteristic of copolymer is a major factor of destabilisation efficiency.

\section{ACKNOWLEDGMENTS}

Discussions with Pr. V. Hlady (Department of Bioengineering, University of Utah, Salt Lake City, USA) are gratefully acknowledged. Atomic Force Microscopy experiments were carried out in the "Service d'Analyses Physicochimiques" (UTC, France) thanks to Frédéric Nadaud.

\section{REFERENCES}

1 Papirer E., Bourgeois C., Siffert B., Balard H. (1982) Chemical Nature and Water/Oil Emulsifying Properties of Asphaltenes, Fuel 61, 732-734. 

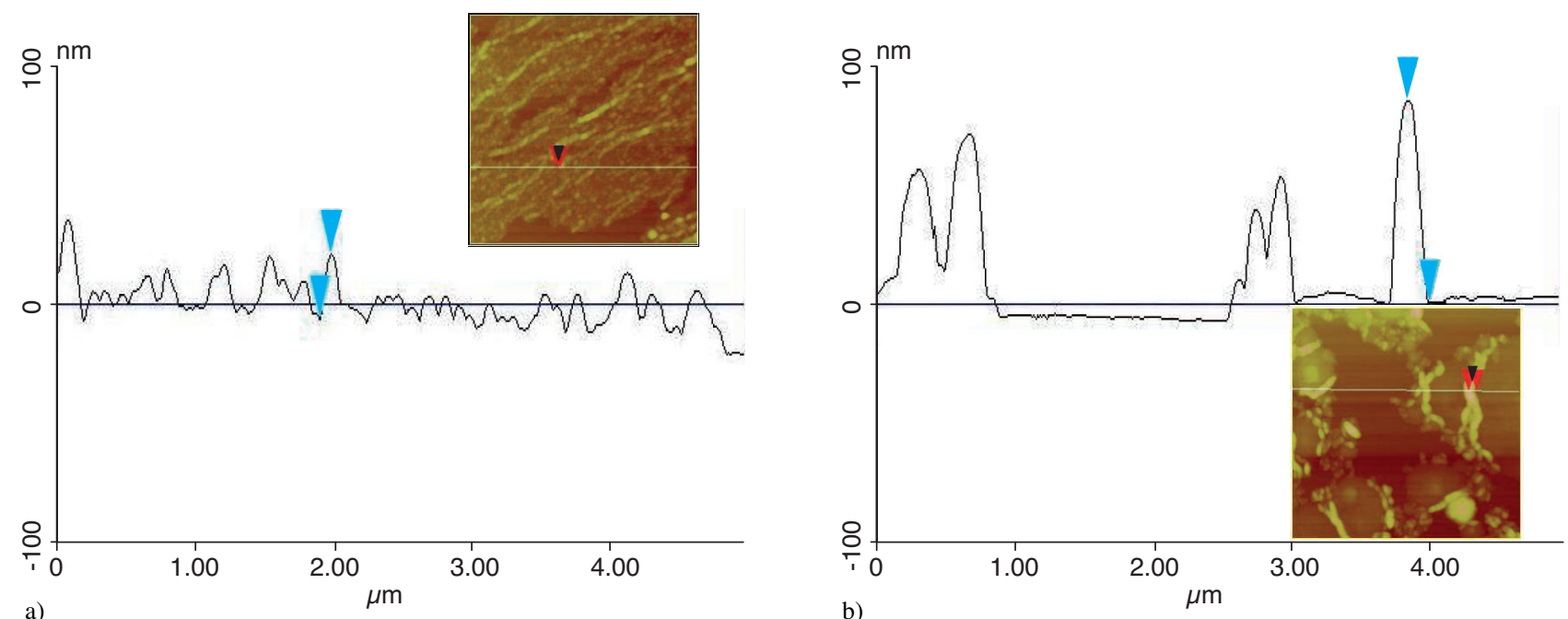

Figure 6

(a) Profile showing the topography of pure asphaltene film (concentration of asphaltene in deposited solution is $0.1 \% \mathrm{w} / \mathrm{w}$ ).

(b) Profile showing the topography of mixed asphaltene/copolymer A film (concentrations of asphaltenes and copolymer A in deposited solution are $0.1 \%$ and $0.01 \% \mathrm{w} / \mathrm{w}$ respectively).

2 Canevari G.P. (1982) The Formulation of an Effective Demulsifier for Oil Spill Emulsions, Mar. Pollut. Bull. 13, 49-54.

3 Bridié A.L., Wanders T.H., Zegveld W., van der Heide H.B. (1980) Formation, Prevention and Breaking of Sea Water in Crude Oil Emulsions "Chocolate Mousses", Mar. Pollut. Bull. 11, 343-348.

4 McMahon A.J. (1992) Interfacial Aspects of Water-In-Crude Oil Emulsion Stability, in Emulsions-A Fundamental and Practical Approach, Sjöblom J. (ed.), Kluwer Academic Publishers, Netherlands.

5 Schramm L.L. (1992) Emulsions: Fundamentals and Applications in the Petroleum Industry, American Chemical Society (ed.), Washington.

6 Angle C.W. (2001) Chemical Demulsification of Stable Crude Oil and Bitumen Emulsions in Petroleum Recovery, in Encyclopaedic Handbook of Emulsion Technology, Sjöblom J. (ed), Marcel Dekker, New York.

7 Sjöblom J., Johnsen E.E., Westvik A., Ese M.H., Djuve J., Auflem I.H., Kallevik H. (2001) Demulsifiers in the Oil Industry, in Encyclopaedic Handbook of Emulsion Technology, Sjöblom J. (ed.), Marcel Dekker, New York.

8 Kim Y.H., Nikolov A.D., Wasan D.T., Diaz-Arauzo D.T., Shetty C.S. (1996) Demulsification of Water In Crude Oil Emulsions: Effects of Film Tension, Elasticity, Diffusivity and Interfacial Activity of Demulsifier Individual Components and their Blends, J. Colloid Interf. Sci . 17, 33-53.

9 Mc Lean J.D., Kilpatrick P. (1997) Effects of Asphaltene Solvency on Stability of Water-In-Crude Oil Emulsions, $J$. Colloid Interf. Sci. 189, 242-253.

10 Gafanova O.V., Yarranton W. (2001) The Stabilization of Water-in-Hydrocarbon Emulsions by Asphaltenes and Resins, $J$. Colloid Interf. Sci. 241, 469-478.

11 Pfeiffer J.Ph., Saal R.N. (1940) Asphaltic Bitumen as Colloid System, J. Phys. Chem. 44, 139-149.
12 Eley D.D., Hey M.J., Symonds J.D. (1988) Emulsions of Water in Asphaltene-Containing Oils 1. Droplet Size Distribution and Emulsification, Colloid. Surface. 32, 87-101.

13 Bouriat P., Kerri N.E., Graciaa A., Lachaise J. (2004) Properties of a two-Dimensional Asphaltene Network at the WaterCyclohexane Interface Deduced from Dynamic Tensiometry, Langmuir 20, 7459-7464.

14 Bhardwaj A., Hartland S. (1998) Studies on Build-up of Interfacial Film at the Crude Oil/Water Interface, J. Disper. Sci. Technol. 19, 465-473.

15 Poteau S., Argillier J.F., Langevin D., Pincet F., Perez E. (2005) Influence of $\mathrm{pH}$ on Stability and Dynamic Properties of Asphaltenes and other Amphiphilic Molecules at the Oil-Water Interface, Energ. Fuel. 19, 1337-1341.

16 Yang X., Lu W., Ese M.H., Sjöblom J. (2001) Film Properties of Asphaltenes and Resins, in Encyclopaedic Handbook of Emulsion Technology, Sjöblom J. (ed.), Marcel Dekker, New York.

17 Bauget F., Langevin D., Lenormand R. (2001) Dynamic Surface Properties of Asphaltenes and Resins at the Oil-Air Interface, $J$. Colloid Interf. Sci. 239, 501-508.

18 Ese M.H., Sjöblom J., Djuve J., Pugh R. (2000) An Atomic Force Microscopy Study of Asphaltenes on Mica Surfaces. Influence of Added Resins and Demulsifiers, Colloid Polym. Sci. 278, 532-538.

19 Bhardwaj A., Hartland S. (1993) Study of Demulsification of Water-In-Crude Oil Emulsion, J. Disper. Sci. Technol. 14, 541557.

20 Djuve J., Yang X., Fjellanger I.J., Sjöblom J., Pelizzetti E. (2001) Chemical Destabilization of Crude Oil Based Emulsions and Asphaltene Stabilized Emulsions, Colloid Polym. Sci. 279, 232-239.

21 Krawczyk M.A., Wasan D.T., Shetty C.S. (1991) Chemical Demulsification of Petroleum Emulsions Using Oil-Soluble Demulsifiers, Ind. Eng. Chem. Res. 30, 367-375. 
22 Daniel-David D., Pezron I., Dalmazzone C., Noïk C., Clausse D., Komunjer L. (2005) Elastic Properties of Crude Oil/Water Interface in Presence of Polymeric Emulsion Breakers, Colloid. Surface. A 270-271, 257-262.

23 Daniel-David D., Pezron I., Clausse D., Dalmazzone C., Noïk C., Komunjer L. (2004) Interfacial Properties of a Silicone Copolymer Demulsifier at the Air/Water Interface, Phys. Chem. Chem. Phys. 6, 1570-1574.

24 Espinat D. (1990) Application des Techniques de Diffusion de la Lumière, des Rayons $X$ et des Neutrons à l'Étude des Systèmes Colloïdaux, Éditions Technip, Paris.

25 Fenistein D., Barré L., Frot D. (2000) De l'agrégation à la flocculation des asphaltenes, une description structurale par diffusion de rayonnement, Oil Gas Sci. Technol. 55, 123-128.

26 Zhang L.Y., Xu Z., Masliyah J.H. (2003) Langmuir and Langmuir-Blodgett Films of Mixed Asphaltene and a Demulsifier, Langmuir 19, 9730-9741.

27 Espinat D., Fenistein D., Barré L., Frot D., Briolant Y. (2004) Effects of Temperature and Pressure on Asphaltenes Agglomeration in Toluene. A Light, X-ray, and Neutron Scattering Investigation, Energ. Fuel. 18, 1243-1249.

28 Barré L., Espinat D., Rosenberg E., Scarsella M. (1997) Colloidal Structure of Heavy Crudes and Asphaltene Solutions, Oil Gas Sci. Technol. 52, 161-175.

29 González G., Middea A. (1987) Asphaltene Adsorption by Quartz and Feldspar, J. Disper. Sci. Technol. 8, 525-548.

30 Ekholm P., Blomberg E., Claesson P., Auflem I.H., Sjöblom J., Kornfeldt A. (2002) A Quartz Crystal Microbalance Study of the Adsorption of Asphaltenes and Resins onto a Hydrophilic Surface, J. Colloid Interf. Sci. 247, 342-350.
31 Acevedo S., Ranaudo M.A., Escobar G., Gutiérrez L., Ortega P. (1995) Adsorption of Asphaltenes and Resins on Organic and Inorganic Substrates and Their Correlation with Precipitation Problems in Production Well Tubing, Fuel 74, 595-598.

32 Pernyeszi T., Patzkó Á., Berkesi O., Dékány I. (1998) Asphaltene Adsorption on Clays and Crude Oil Reservoir Rocks, Colloid. Surface. A 137, 373-384.

33 Marczewski A.W., Szymula M. (2002) Adsorption of Asphaltenes from Toluene on Mineral Surface, Colloid. Surface. A 208, 259-266.

34 Acevedo S., Castillo J., Fernández A., Goncalves S., Ranaudo M.A. (1998) A Study of Multilayer Adsorption of Asphaltenes on Glass Surfaces by Photothermal Surface Deformation. Relation of this Adsorption to Aggregate Formation in Solution, Energ. Fuel. 12, 386-390.

35 González G., Middea A. (1988) The Properties of the CalciteSolution Interface in the Presence of Adsorbed Resins or Asphaltenes, Colloid. Surface. 33, 217-229.

36 Nevskaia D.M., Guerrero-Ruíz A., López-González J.D. (1996) Adsorption of Polyoxyethylenic Surfactants on Quartz, Kaolin, and Dolomite: A Correlation between Surfactant Structure and Solid Surface Nature, J. Colloid Interf. Sci. 181, 571-580.

37 Powell D.E., Carpenter J.C. (1997) Polyethermethylsiloxanes, Organosilicone Materials, in Handbook of Environmental Chemistry, Chandra G. (ed.), Springer, New York.

38 Wilde P., Mackie A., Husband F., Gunning P., Morris V. (2004) Proteins and Emulsifiers at Liquid Interfaces, Adv. Colloid Interfac. 91, 221-293.

Final manuscript received in July 2007 